\title{
Hacia una docencia inclusiva en la Educación Superior: La investigación sobre la propia práctica docente como herramienta de transformación
}

\author{
Towards an inclusive teaching in Higher Education: \\ Analysis of one's own teaching practice as an \\ improvement tool
}

\section{Viviana Sobrero ${ }^{\mathrm{a}}$}

ajefa de Área de Gestión de la Formación, Departamento de Pregrado Vicerrectoría de Asuntos Académicos, Universidad de Chile. Chile

Transitamos una época compleja marcada por fuertes tensiones que atraviesan a la educación y a la educación superior en particular. Al tiempo en que vivimos la llamada revolución científico-tecnológica, la transnacionalización de la generación y difusión del conocimiento, la internacionalización de la propia institución universitaria y el intercambio constante y fluido entre personas de distintos puntos del planeta, sigue pendiente el reto crucial de garantizar un desarrollo humano sustentable y equitativo, que concilie el crecimiento con la equidad y logre articular el desarrollo y su democratización.

Los estudios nacionales e internacionales indican que entre los países de América Latina, Chile es uno de los que presentan una mayor desigualdad en la distribución de ingresos ${ }^{1}$. Dicha desigualdad encuentra su correlato en un sistema educativo altamente segmentado y estratificado ${ }^{2}$.

En una sociedad marcada por esta tensión, la democratización de la educación es una tarea de primer orden. El enfoque de inclusión cobra particular relevancia, no sólo como condición ligada al derecho a la educación y al aprendizaje a lo largo de la vida, sino también como camino para consolidar sociedades democráticas que brinden a todas las personas oportunidades de desarrollar su potencial, con miras a un futuro sostenible y una existencia plena y digna.

En una de las publicaciones recientes de la UNESCO: "Rethinking Education: Towards a global common good?"', se resalta la necesidad de reafirmar una visión humanista de la educación, cuyo propósito central es promover la dignidad, capacidad y bienestar de los seres humanos en su relación con otros y con la naturaleza. Implica, también, una preocupación por el desarrollo humano y social sostenible; lo que supone asumir un enfoque de educación que no excluya ni margine.

En lo que respecta a la educación superior, tanto las demandas ciudadanas y los estudios locales -que han impulsado en gran medida las iniciativas de reforma del sector en el país- como el consenso alcanzado por organismos internacionales desde distintas perspectivas $^{4}$, hacen un llamado a las universidades a fortalecer la equidad; aportar a la inclusión y el aprendizaje efectivo de grupos y personas históricamente excluidas de la educación superior; reconocer el valor de la di- 
versidad en la calidad de los procesos de aprendizaje y el desarrollo del conocimiento y valorar la diversidad como contexto para la formación ciudadana en pro de la democracia y la paz.

Ante estos desafíos, durante los últimos años, y en conformidad a su misión histórica, la Universidad de Chile ha diseñado estrategias para avanzar hacia una mayor inclusión y equidad desde una perspectiva de sustentabilidad universitaria ${ }^{5}$, en el marco de la excelencia que la caracteriza.

Desde este enfoque, que entiende la equidad y la inclusión como una cuestión de derechos, las distintas problemáticas que afectan a las trayectorias académicas de los estudiantes se comprenden como ámbitos de responsabilidad compartida entre los estudiantes y la institución que los recibe, por lo que a la universidad le corresponde la generación de recursos y oportunidades formativas adecuadas para que los estudiantes logren los aprendizajes esperados ${ }^{6}$.

A diferencia de la noción de igualdad -que exige un mismo trato para todos- la equidad supone una atención diferenciada según las necesidades y condiciones particulares de individuos y grupos específicos. En este sentido, la noción de equidad parte del reconocimiento de la existencia de desigualdades sociales. Se entiende, por tanto, que el concepto se basa en un ideal de justicia correctiva, según el cual el trato igualitario en los distintos tramos del sistema (acceso, permanencia, egreso) estaría atentando contra la equidad y la justicia al invisibilizar las desventajas que algunos traen por distintas condiciones ${ }^{7}$.

Una docencia que promueva la equidad requiere considerar las diferencias existentes entre los estudiantes, no desde un enfoque normativo -que entiende la diferencia como déficit o carencia- sino desde un enfoque que potencie sus capacidades y les permita una inclusión plena, activa y creativa a la cultura universitaria que los acoge.

De este modo, sin abandonar la rigurosidad científica y la excelencia académica, la Universidad de Chile adopta un enfoque propuesto por Alexander Astin para definir la calidad educativa como la capacidad de desarrollar al máximo los talentos de la institución y de todas las personas que participan en ella en un marco de equidad, y de aprendizaje institucional ${ }^{8}$. Desde esta perspectiva, la equidad y la inclusión son condiciones ineludibles para hablar de calidad.

Estas transformaciones exigen replantear profundamente los procesos formativos institucionales y los tipos de interacción social que estos procesos promueven, así como los modelos de docencia y acogida para los estudiantes.

Si bien, consolidar practicas docentes de excelencia en un contexto de creciente diversidad y con perspectiva inclusiva en la Universidad de Chile supone un camino en el que se deben conjugar debate, acción, investigación, aprendizajes y transformación y en el que se involucre a toda la comunidad universitaria en múltiples niveles, los académicos, en su rol docente, juegan un rol fundamental.

Con el compromiso de profundizar la consolidación de un enfoque para abordar la docencia universitaria inclusiva -que sitúa al estudiante y sus procesos de aprendizaje como centro del proceso formativo- el Departamento de Pregrado inició este año el Plan de desarrollo Docente que, por definición, conjuga formación, innovación, evaluación e investigación docente.

Desde un enfoque de docencia inclusiva, los profesores no solo deben saber en profundidad aquello que enseñan, sino también deben conocer a sus estudiantes y saber cómo favorecer el aprendizaje de todos y cada uno.

El dominio de estos tres saberes no se clausura a lo largo de la carrera docente universitaria. Es un desafío constante mantenerse actualizado respecto del saber disciplinar, conocer las particularidades y ritmos de cada nueva generación de estudiantes y saber cómo potenciar en cada uno de ellos de mejor manera sus capacidades, entendiendo además que lo que funciona con un grupo de estudiantes puede no ser atingente a otro. Este desafío constante que supone la docencia, permite hacer de esta práctica humana y social, una actividad viva, nunca mecánica, que involucra al docente cognitiva, afectiva, emocional y éticamente.

En este escenario, la reflexión y la investigación sobre la propia práctica docente cobra un papel potenciador fundamental'.

A diferencia de lo que ocurre en el ámbito de la investigación disciplinar, el propósito de la investigación educativa no se reduce a la producción de conocimiento para incrementar el cuerpo teórico del saber pedagógico o educativo. Dado el carácter situacional, específico y singular del conocimiento que emerge de la investigación educativa en la interacción con estudiantes, su máximo valor reside en tanto permite la comprensión y transformación de las propias prácticas de quienes participan en cada situación.

De este modo, la investigación educativa se propone salvar la tensión entre la teoría y la práctica, entre la investigación y la acción, formando y transformando el conocimiento y la acción de quienes participan en ella, experimentando, al mismo tiempo que investigando o reflexionando con otros sobre el propio quehacer, en un marco de colaboración y aprendizaje conjunto.

Valorar la diversidad como un aporte para el desarrollo del conocimiento y como una oportunidad para ser mejores, requiere de una comunidad universitaria 
fortalecida a través de la generación de instancias de colaboración entre académicos, estudiantes, directivos y funcionarios; una comunidad que entiende su rol en contextos de diversidad, reflexiona en torno al problema y es capaz de implementar las estrategias definidas en conjunto. Esa es la invitación y el gran desafío al que estamos llamados a enfrentar todas y todos.

\section{Conflicto de intereses:}

La autora declara no tener conflicto de intereses.

\section{Referencias}

1. Cepal, 2010; Cepal (2010). Panorama social de América Latina. Recuperado de http://www.cepal.org/publicaciones/ xml/9/41799/PSE-panoramasocial2010. pdf

2. OCDE 2009, La educación superior en Chile. Recuperado de http://www.oecdilibrary.org/la- educacion-superior-enchile_5ksntst3t7hd.pdf

3. Replantear la educación como un bien común mundial. UNESCO 2015. http://unesdoc.unesco.org/ images/0023/002326/232697s.pdf
4. Conferencia Regional de Educación Superior 2008; OCDE, 2009; Agenda Unesco 2030 para el Desarrollo Sustentable. Objetivo $\mathrm{N}^{\circ} 4$.

5. Política de Equidad e Inclusión. Senado Universitario, Universidad de Chile, 2014; Politica de Sustentabilidad Universitaria. Senado Universitario. Universidad de Chile, 2012.

6. Donoso S, Cancino V. Caracterización socioeconómica de los estudiantes de educación superior. Revista Calidad en la Educación 2007; 26: 203-44.

7. Blanco R. Educación de calidad para todos: un asunto de derechos y justicia social. En Organización de Estados Iberoamericanos para la Educación la Ciencia y la Cultura (Ed.), Desde la educación como derecho social hasta la renovación de las prácticas docentes. Santiago, Chile: Fundación Santillana. 2008; pp. 13-53

8. Adaptado de Alexander Astin. Assessment for excellence: The philosophy and practice of assessment and evaluation in higher education. Rowman \& Littlefield Publishers. 2012.

9. Elliott J. El cambio educativo desde la investigación-acción. Madrid: Morata. 1993. 